\title{
TCEC Cup 3
}

Article

Accepted Version

The TCEC Cup 3 report

Haworth, G. and Hernandez, N. (2019) TCEC Cup 3. ICGA Journal, 41 (3). pp. 168-173. ISSN 1389-6911 doi: https://doi.org/10.3233/ICG-190114 Available at https://centaur.reading.ac.uk/83157/

It is advisable to refer to the publisher's version if you intend to cite from the work. See Guidance on citing.

Published version at: https://content.iospress.com/articles/icga-journal/icg 190114

To link to this article DOI: http://dx.doi.org/10.3233/ICG-190114

Publisher: The International Computer Games Association

All outputs in CentAUR are protected by Intellectual Property Rights law, including copyright law. Copyright and IPR is retained by the creators or other copyright holders. Terms and conditions for use of this material are defined in the End User Agreement.

\section{www.reading.ac.uk/centaur}

\section{CentAUR}

Central Archive at the University of Reading

Reading's research outputs online 


\section{TCEC Cup 3}

Guy Haworth and Nelson Hernandez ${ }^{1}$

Reading, UK and Maryland, USA

The second TCEC Cup (Haworth and Hernandez, 2019a) was won by 'LC0' LEELA CHESS ZERO beating HOUDINI after the latter surprisingly took out STOCKFISH in their semi-final. The event, with its Rapid tempo of $30^{\prime}+5^{\prime \prime} /$ move continued to be the favoured curtain-raiser before the current TCEC season's Superfinal (Haworth and Hernandez, 2019b). TCEC Cup 3 began on April $29^{\text {th }} 2019$.

The following engines sent in updates for the cup: ALLIESTEIN, ARASAN, FIRE, GINKGO, KOMODO, KOMODOMCTS, LCZERO, MARVIN, NEMORINO, RODENT III, ROFCHADE, RUBICHESS, STOCKFISH, VAJOLET2, WASP, WINTER and XIPHOS. The settings of CHIRON and PIRARUCU were changed. So clearly, the international computer chess programme continues on its dynamic way (CPW, 2019). The engine logos are listed in Fig. 1.

The 'standard pairing' was again used, with seed $s$ playing seed $2^{6-r}-s+1$ in round $r$ if the wins all go to the higher seed. Thus, seed $s 1$ plays $s 32, s 16, \ldots, s 2$ if all survive long enough. The higher seed is listed first in Table 1 . This time, the matches - eight games plus any necessary game-pair tiebreaks - were played out only until the result was decided.

The usual 'TCEC opening' team, the second author here and Jeroen Noonen, randomly chose from three books wiith some regard for frequency over the board. Greater variety of play ensued from round 1's 8ply openings and 12-ply openings thereafter up to and including the semi-finals. The final took openings of various lengths from JN's TCEC Superfinal books for seasons 9-14.

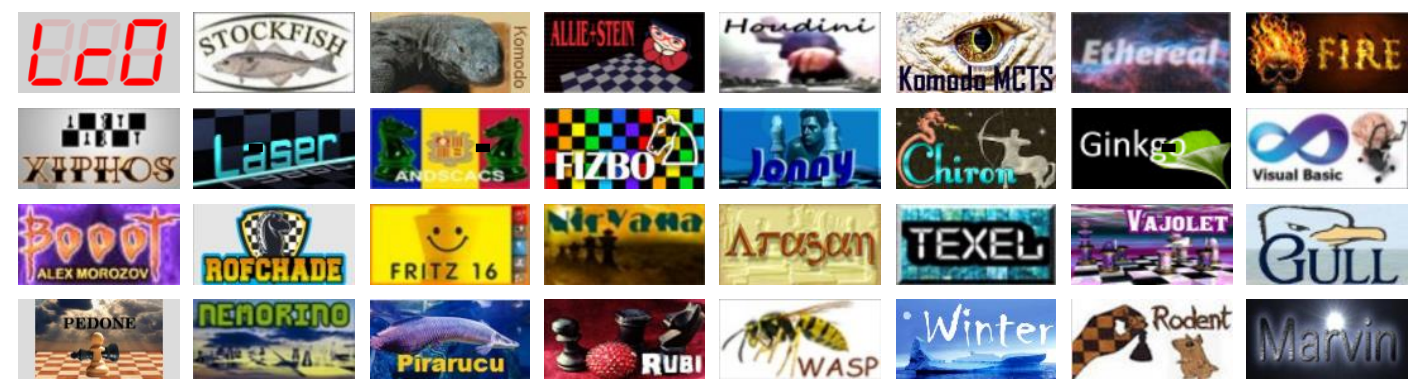

Fig. 1. Logos for TCEC Cup engines in seeded order (LeELA CHESS ZERO $\rightarrow$ STOCKFISH $\rightarrow \ldots \rightarrow$ MARvin).

As in previous TCEC Cup events, interest focused on actual performance ' $\% \mathrm{P}$ ' compared with expected performance ' $\mathrm{E} \% \mathrm{P}$ ' implied by TCEC ELO difference 'ELO $\Delta$ '. The accuracy of the TCEC ELOs, the upgrades to over half the field and the character of the random openings were to be the main influences.

\footnotetext{
${ }^{1}$ Corresponding author: g.haworth@ reading.ac.uk
} 
Table 1. TCEC Cup 3: round one results from the winner's perspective ${ }^{2,3}$

\begin{tabular}{|c|c|c|c|c|c|c|c|c|c|c|c|}
\hline$\alpha \beta$ & $\#$ & $\stackrel{B}{g}$ & $\begin{array}{c}\text { Elo } \\
\Delta\end{array}$ & Elo & $\dot{\vec{\theta}}$ & 苋 & Round 1 Pairings & E\%P & Round 1 Results & $\% \mathbf{P}$ & ?? \\
\hline Lc & 01 & $\checkmark$ & 547 & 3587 & $\mathrm{P}$ & 01 & Leela Chess Zero 0.21.1-nT40.T6.532 & 97.20 & Jeela Chess Zero 5-0. 11111 & 10000 & $=$ \\
\hline $\mathrm{Ma}$ & 01 & $\checkmark$ & 541 & 3040 & 4 & 32 & Marvin 3.4.0-a1 & $\int_{02.80}$ & Leela Chess Zero, J-0: 11111 & 100.00 & $=$ \\
\hline $\mathrm{Cb}$ & 02 & & 26 & 3352 & 2 & 16 & ChessBrainVB 3.72 & 46.37 & 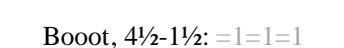 & 25.00 & --- \\
\hline Bo & 02 & & 20 & 3378 & 2 & 17 & Booot 6.3.1 & 53.63 & Booot, $4^{1 / 2}-1 / 2:=1=1=1$ & 25.00 & --- \\
\hline $\mathrm{Fi}$ & 03 & $\checkmark$ & 167 & 3458 & 1 & 08 & Fire 021819 & 72.06 & Fire, $4^{1 / 2-1 / 2: 111=1}$ & 90.00 & + \\
\hline $\mathrm{Pe}$ & & & $16 /$ & 3291 & 4 & 25 & Pedone 1.9 & 了 27.94 & Fire, $41 / 2^{-1 / 2}$ & 90.00 & + \\
\hline $\mathrm{Xi}$ & 04 & $\checkmark$ & 163 & 3463 & 1 & 09 & Xiphos 0.5 .3 & 71.58 & Xinhes $41 / 2-21 / 2 \cdot--1---1$ & 6429 & - \\
\hline $\mathrm{Gu}$ & & & & 3300 & 3 & 24 & Gull 3 & 28.42 & Xiphos, $44^{\prime \prime 2}-2^{1 / 2}:==1==-1$ & 64.29 & - \\
\hline AS & 05 & $\checkmark$ & 277 & 3452 & $\mathrm{P}$ & 04 & AllieStein $0.3-n 6.1$ & 83.39 & AllieStein, 5-0: 11111 & 100.00 & + \\
\hline Wa & & $\checkmark$ & & 3175 & 4 & 29 & Wasp 3.61 & 16.61 & Amestem, J-U: 11111 & 100.00 & + \\
\hline Jo & 06 & & 108 & 3380 & 2 & 13 & Jonny 8.1 & 64.73 & Jonny $5-1 \cdot=11=11$ & 83.33 & + \\
\hline $\mathrm{Ni}$ & & & & 3272 & 3 & 20 & Nirvana 2.4 & 35.27 & & & \\
\hline Ho & 07 & & 413 & 3545 & $P$ & 05 & Houdini 6.03 & 92.58 & Houdini 5-0. 11111 & 10000 & + \\
\hline $\mathrm{Ru}$ & $0 /$ & $\checkmark$ & 413 & 3132 & 4 & 28 & RubiChess 1.4 & 07.42 & Houdini, J-0: 11111 & 100.00 & + \\
\hline $\mathrm{Fz}$ & 08 & & 52 & 3393 & 1 & 12 & Fizbo 2 & 57.22 & Fizbo, $4 \frac{1}{2} 2-31 \frac{1}{2}$ : ======1= & 56.25 & $=$ \\
\hline $\mathrm{Ar}$ & 08 & $\checkmark$ & 52 & 3341 & 3 & 21 & Arasan 21.3 & 42.78 & FIZDO, 4t/2-3/2: =-=-=-1= & 50.25 & $=$ \\
\hline St & 09 & $\checkmark$ & 540 & 3589 & $\mathrm{P}$ & 02 & Stockfish 19042711 & 97.06 & Stockfish, $4^{1} \frac{1}{2^{-1} / 2:} 1=111$ & 90.00 & _- \\
\hline Ro & 09 & $\checkmark$ & 540 & 3049 & 4 & 31 & Rodent III 0.278 & 了 02.94 & Stocki1sh, $4^{1 / 2-1 / 2: 1=111}$ & 90.00 & - \\
\hline $\mathrm{Gi}$ & 10 & $\checkmark$ & 62 & 3409 & 2 & 15 & Ginkgo S13 & 58.59 & Ginkgo, $71 \frac{1}{2}-61 / 2$ : & 5357 & - \\
\hline $\mathrm{rf}$ & 10 & $\checkmark$ & 02 & 3347 & 2 & 18 & rofChade 2.1 & 与 41.41 & $01======,====1=$ & 53.51 & \\
\hline Et & 11 & & 184 & 3461 & 1 & 07 & Ethereal 11.38 & 74.02 & Ethereal $412-1 / 2 \cdot 1=111$ & 9000 & + \\
\hline $\mathrm{Ne}$ & & $\checkmark$ & 104 & 3277 & 4 & 26 & Nemorino 5.13 & 25.98 & Etnereal, $4 / 22^{-1 / 2}$ & & \\
\hline $\mathrm{La}$ & 12 & & 152 & 3435 & 1 & 10 & Laser 230319 & 70.26 & Laser, 5-2: $11====1$ & 71.43 & $=$ \\
\hline $\mathrm{Va}$ & 12 & $\checkmark$ & 152 & 3283 & 3 & 23 & Vajolet2 2.7 & 29.74 & & & \\
\hline Ко & 13 & $\checkmark$ & 555 & 3540 & $\mathrm{P}$ & 03 & Komodo 2319.0 & 97.40 & Komodo, $4^{1} \frac{1}{2-1 / 2}: 111=1$ & 90.00 & - \\
\hline Wi & & $\checkmark$ & & 2985 & 4 & 30 & Winter 0.5.5b & 02.60 & 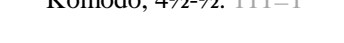 & 90.00 & \\
\hline $\mathrm{Ch}$ & 14 & $\checkmark$ & 54 & 3359 & 2 & 14 & Chiron 230119 & 57.50 & Chiron, $4 \frac{1}{2} 2-2^{1 / 22:} 10=11==$ & 64.29 & + \\
\hline $\mathrm{Fr}$ & & & 54 & 3305 & 3 & 19 & Fritz 16.10 & 42.50 & Cniron, $4 \frac{1}{2-2-2 / 2}$ : $10=11==$ & 04.29 & + \\
\hline $\mathrm{Km}$ & 15 & $\checkmark$ & 299 & 3481 & $\mathrm{P}$ & 06 & KomodoMCTS 2322.00 & 85.23 & KomodoMCTS, 5-0: 11111 & 100.00 & + \\
\hline pi & & $\checkmark$ & & 3182 & 4 & 27 & pirarucu 2.9.5 & 14.77 & & & \\
\hline An & 16 & & 174 & 3440 & 1 & 11 & Andscacs 0.95123 & 72.87 & Andscacs, $4 \frac{1}{2}-2-1 \frac{1}{2} 2: 1=011==$ & 64.29 & _- \\
\hline $\mathrm{Te}$ & & & & 3266 & 3 & 22 & Texel 1.08a13 & 27.13 & Alluseads, $472-272.1-011--$ & 04.29 & \\
\hline
\end{tabular}

\section{$1 \quad$ Round 1}

As expected, 'LC0' LEELA CHESS ZERO opened its campaign with a 5-0 clean sweep. ALLIESTEIN, HOUDINI and KOMODOMCTS repeated this feat. In the top half of the draw, the eventual winner did not concede a single game but this was to change. Marginal favourite GINKGO lost its first game, won its second and was taken to fourteen games before persevering against ROFCHADE. This was the only comeback and tiebreak of the first round.

The other match-winners to lose a game were CHIRON (to FRITZ) and ANDSCACS (to TEXEL) so 'kudos' to those engines. Best performers relative to expectations were ETHEREAL, AlliESTEIN, FIRE and especially BOOOT which comprehensively eliminated CHESSBRAINVB, the seed above it. The draw between STOCKFISH and RODENT is also well worth a visit. The field was now exclusively TCEC15 Divisions P, 1 and 2 - the top 15 plus seed 17, BOOOT, almost as expected.

\footnotetext{
${ }^{2}$ The higher seed played White first, except for the AS-WA match where an inconsequential glitch omitted game one.

${ }^{3}$ In the $\%$ P column, ' +' ('-') indicates an excess (shortfall) of a $1 / 2$-point by the higher seed in the final score.
} 
BoOOT put up a valiant fight against LC0 in some long and memorable games, particularly game 1 (Kingscrusher, 2019a) but still only scored a half-point. FIRE edged a match win in game seven against immediate rival XIPHOS. STOCKFISH beat GINKGO, g25, the final KRPPKRP just beyond adjudication echoing Carlsen-Caruana WCC 2018, Rapid game 1. LASER scored an early win against ETHEREAL but lost with its last Black of eight. Fifteen draws followed before ETHEREAL nosed ahead to win the longest TCEC Cup match to date. LASER's fans are entitled to be disappointed, having come so close.

Table 2. TCEC Cup 3: round two results from the winner's perspective.

\begin{tabular}{|c|c|c|c|c|c|c|c|c|c|c|c|}
\hline$\alpha \beta$ & $\#$ & 总 & $\begin{array}{c}\text { Elo } \\
\Delta\end{array}$ & Elo & $\dot{\vec{\theta}}$ & छूँ & Round 2 Pairings & E\%P & Round 2 Results & $\% \mathbf{P}$ & $\downarrow$ \\
\hline Lc & 01 & $\checkmark$ & 200 & 3587 & $P$ & 01 & Leela Chess Zero 0.21.1-nT40.T6.532 & 76.78 & Leela Chess Zero $41 / 2-1 / 2 \cdot 1111=$ & 9000 & \\
\hline Bo & & & & 3378 & 2 & 17 & Booot 6.3 .1 & 23.22 & Leera Cness Zero, 4/2-1/2.1111= & 90.00 & \\
\hline $\mathrm{Fi}$ & 02 & $\checkmark$ & 5 & 3458 & 1 & 08 & Fire 021819 & 49.30 & Fire, $4^{1} / 2-3^{1} / 2$ : $======1=$ & 56.25 & + \\
\hline $\mathrm{Xi}$ & 02 & $\checkmark$ & & 3463 & 1 & 09 & Xiphos 0.5.3 & 50.70 & & $50.2 \mathrm{~J}$ & \\
\hline AS & 03 & $\checkmark$ & 72 & 3452 & $\mathrm{P}$ & 04 & AllieStein 0.3-n6.1 & 59.95 & AllieStein, $4 \frac{112-1 / 2: 111=1}{}$ & 90.00 & +\# \\
\hline Jo & 05 & & 12 & 3380 & 2 & 13 & Jonny 8.1 & 40.05 & 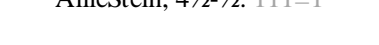 & 10.00 & \\
\hline Ho & 04 & & 152 & 3545 & $\mathrm{P}$ & 05 & Houdini 6.03 & 70.26 & Houdi & 75.00 & + \\
\hline $\mathrm{Fz}$ & & & & 3393 & 1 & 12 & Fizbo 2 & 29.74 & & & \\
\hline St & 05 & $\checkmark$ & 180 & 3589 & $\mathrm{P}$ & 02 & Stockfish 19042711 & 73.57 & Stockfish, $4 \frac{1}{2} 2-1 \frac{1}{2} 2: 1===11$ & 75.00 & $=$ \\
\hline $\mathrm{Gi}$ & & $\checkmark$ & & 3409 & 2 & 15 & Ginkgo S13 & 26.43 & & & \\
\hline Et & 06 & & 26 & 3461 & 1 & 07 & Ethereal 11.38 & 53.63 & Ethereal, 121/2-11¹/2: & 52.08 & - \\
\hline $\mathrm{La}$ & & & & 3435 & 1 & 10 & Laser 230319 & 46.37 & $=0====1=,=(\times 14), 1=$ & & \\
\hline Ko & 07 & $\checkmark$ & 181 & 3540 & $P$ & 03 & Komodo 2319.0 & 73.68 & Komodo, 5-1: 1==111 & 83.33 & + \\
\hline $\mathrm{Ch}$ & & $\checkmark$ & 101 & 3359 & 2 & 14 & Chiron 230119 & 26.32 & & 年 & \\
\hline $\mathrm{Km}$ & 08 & $\checkmark$ & 41 & 3481 & $P$ & 06 & KomodoMCTS 2322.00 & 55.71 & KomodoMCTS, 5-3: ====1==1 & 62.50 & + \\
\hline An & & & 41 & 3440 & 1 & 11 & Andscacs 0.95123 & 44.29 & & & \\
\hline
\end{tabular}

\section{The quarter-finals, semi-finals, third-place play-off and final}

LEELA, by virtue of being top seed, gets the lowest seed left as long as results go with seeding. However, at this stage, no match is easy. LEELA duly overcame FIRE but it was only after a great fight, a credit to both sides. HoudinI, like BoOOT in Round 1, overturned the seed immediately above it, in this case ALLIESTEIN.

Table 3. TCEC Cup 3: quarter-final results from the winner's perspective.

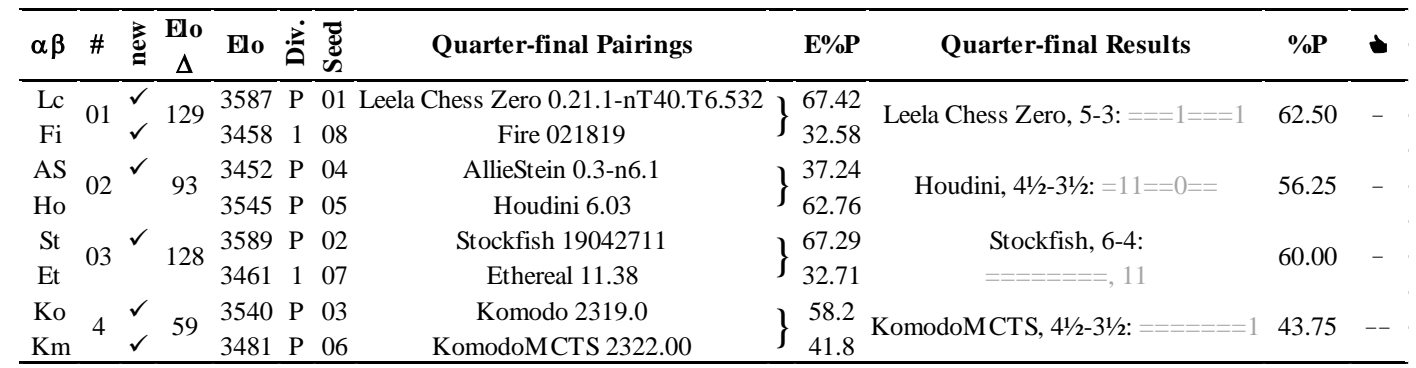

In the lower half of the draw, ETHEREAL surprised the growing audience and STOCKFISH with a straight eight draws but then STOCKFISH reeled off two wins - the second of which it could arguably have lost 
after 28. ... Rbd8. Enter the dragons, KOMODO and KOMODOMCTS, over-hungry after the delay and more than ready for a fight, see Fig. 2. After much effort, the upstart newcomer overturned the seeding even more than HOUDINI, its win in the last of the eight scheduled games allowing no response.

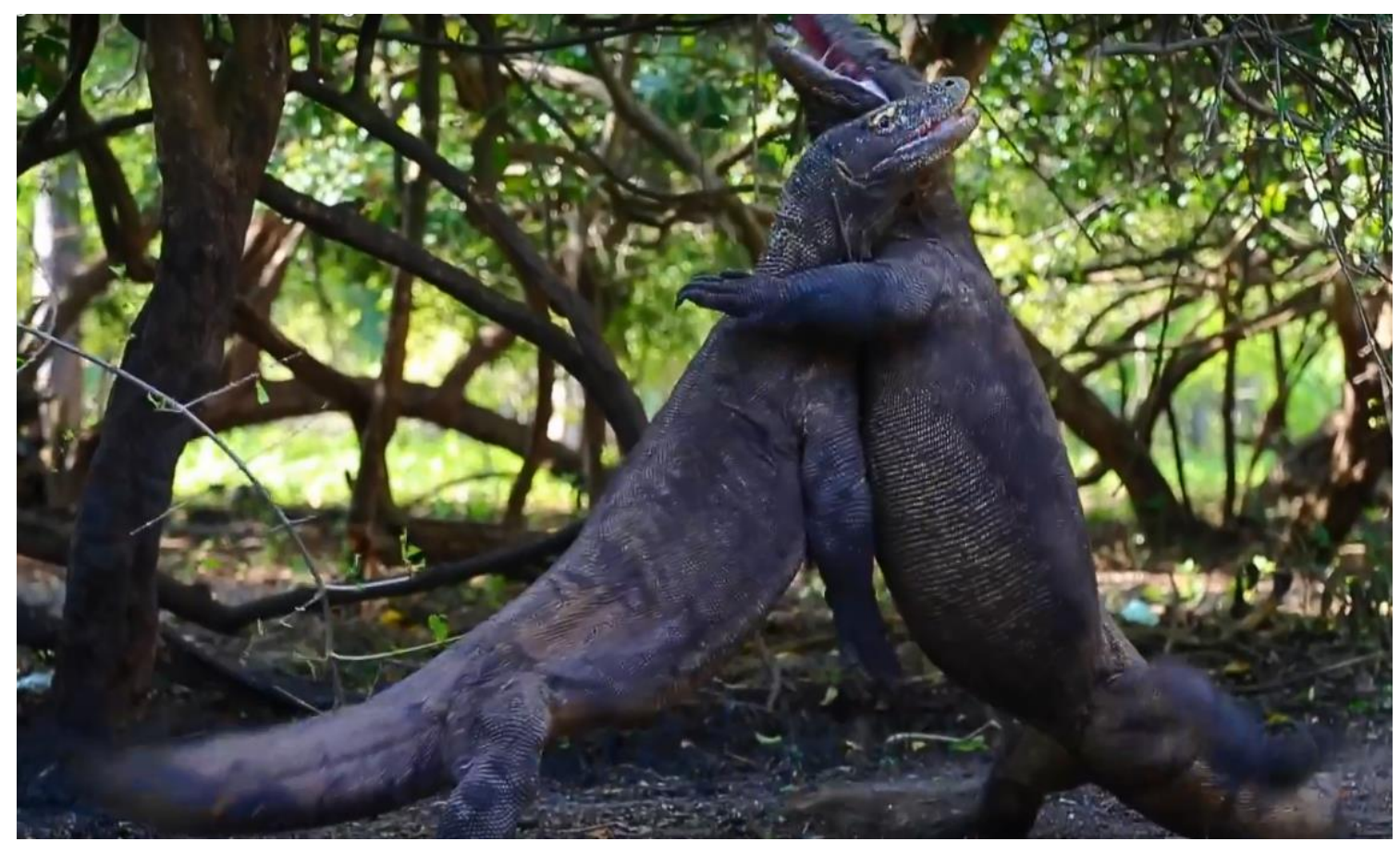

Fig. 2. Two Komodo dragons head-to-head: fighting, not foreplay. Ringside seats still available.

Table 4. TCEC Cup 3: semi-final results from the winner's perspective.

\begin{tabular}{|c|c|c|c|c|c|c|c|c|c|}
\hline$\alpha \beta$ & $\#$ & 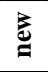 & $\begin{array}{c}\text { Elo } \\
\Delta\end{array}$ & 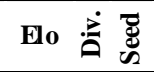 & Semi-final Pairings & E\%P & Semi-final Results & $\% \mathbf{P}$ & $\downarrow$ \\
\hline $\begin{array}{l}\text { Lc } \\
\text { Ho }\end{array}$ & 01 & $\checkmark$ & 42 & $\begin{array}{lll}3587 & \mathrm{P} & 01 \\
3545 & \mathrm{P} & 05\end{array}$ & $\begin{array}{l}\text { Leela Chess Zero 0.21.1-nT40.T6.532 } \\
\text { Houdini } 6.03\end{array}$ & $\begin{array}{l}55.84 \\
44.16\end{array}$ & Leela Chess Zero, 41/2-21/2: $1=====1$ & 64.29 & + \\
\hline $\begin{array}{c}\mathrm{St} \\
\mathrm{Km}\end{array}$ & 02 & $\begin{array}{l}\checkmark \\
\checkmark \\
\end{array}$ & 108 & $\begin{array}{lll}3589 & \mathrm{P} & 02 \\
3481 & \mathrm{P} & 06 \\
\end{array}$ & $\begin{array}{c}\text { Stockfish } 19042711 \\
\text { KomodoMCTS } 2322.00\end{array}$ & $\begin{array}{l}64.73 \\
35.27 \\
\end{array}$ & Stockfish, $4 \frac{1}{2}-2-\frac{1}{2}:==1===1$ & 64.29 & $=$ \\
\hline
\end{tabular}

In the semi-final, the favourites were not challenged and came through, both being unbeaten so far. This left HOUDINI to face KOMODOMCTS in the play-off for third. This was won comfortably by HOUDINI which continues to impress at this level despite not being updated.

Table 5. TCEC Cup 3: the HoudinI - KomodoMCTS play-off and the LeELA Chess Zero-STOCKFISH final.

\begin{tabular}{|c|c|c|c|c|c|c|c|c|c|}
\hline$\alpha \beta$ & $\#$ & $\stackrel{2}{=}$ & $\begin{array}{c}\text { Elo } \\
\Delta\end{array}$ & 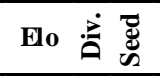 & Small Final \& Final Pairings & E\%P & Results & $\% \mathbf{P}$ & $\downarrow$ \\
\hline $\begin{array}{l}\mathrm{Ho} \\
\mathrm{Km}\end{array}$ & 02 & $\checkmark$ & 64 & $\begin{array}{lll}3545 & \mathrm{P} & 05 \\
3481 & \mathrm{P} & 06\end{array}$ & $\begin{array}{c}\text { Houdini } 6.03 \\
\text { KomodoMCTS } 2322.00\end{array}$ & $\begin{array}{l}58.9 \\
41.1\end{array}$ & Houdini, $41 \frac{1}{2}-2 \frac{1}{2} 2: 1===1==$ & 64.29 & + \\
\hline $\begin{array}{l}\mathrm{Lc} \\
\mathrm{St}\end{array}$ & 01 & $\checkmark$ & 2 & $\begin{array}{lll}3587 & \mathrm{P} & 01 \\
3589 & \mathrm{P} & 02\end{array}$ & $\begin{array}{c}\text { Leela Chess Zero 0.21.1-nT40.T6.532 } \\
\text { Stockfish 19042711 }\end{array}$ & $\begin{array}{l}49.72 \\
50.28\end{array}$ & $\begin{array}{l}\text { Leela Chess Zero, } 5^{1 / 2-41 / 2} \text { : } \\
==1====0,1=\end{array}$ & 55.00 & + \\
\hline
\end{tabular}


In the final, LEELA's game 3 win was not decisive as STOCKFISH won convincingly in the last scheduled game. The tie-break then ensued and LEELA ironically took advantage of two rare but not unknown 7man STOCKFISH errors (Aloril, 2019), here in positions 155b and 167w. LEELA progressed to the win without its usual hesitancy as it now had the use of the 6-man EGTs. Fig. 3 shows the defence, the valueand depth-shedding errors and the progress to the win. In the return game, LEELA eroded STOCKFISH's initial advantage and then attacked in a drawn position: only perpetual checks across 100 moves prevented STOCKFISH from being mated.
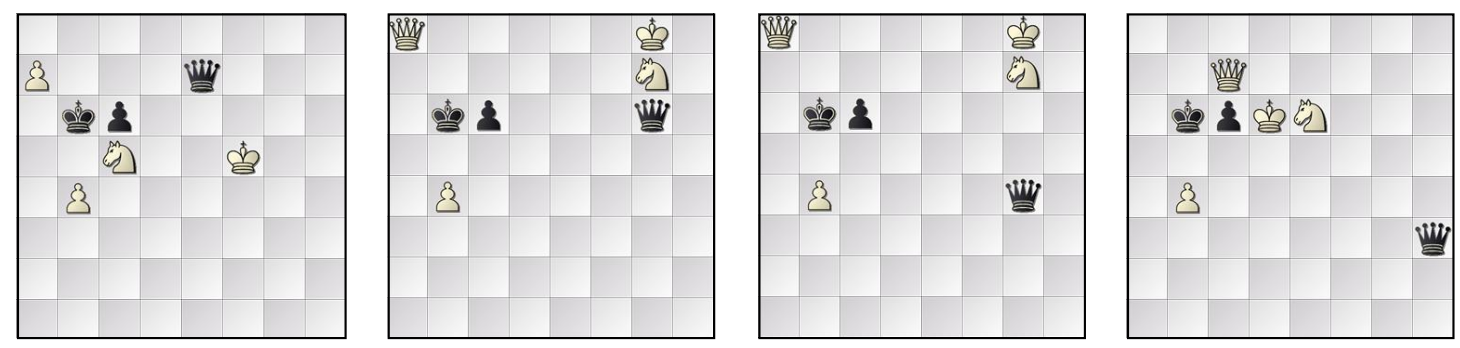

Fig. 3. Final, g9, Lc-St: (a) 124w, drawn; (b) 155b, drawn; (c) 156w, possible win (plycount = 63p, dtz = 43p); (d) $167 \mathrm{~b}$, winnable despite the 50-move-rule (plycount $=86 \mathrm{p}, \mathrm{dtz}=8 \mathrm{p}$ ).

\section{A summary}

The early rounds went very much as predicted by the form book though several losers put up stronger resistance than expected. At the top level, few mistakes were made by the closely-matched engines so in the short matches anything could have happened. Nevertheless, LEELA confirmed that its win in TCEC Cup 2 was no fluke and it retained the title. Neural networks do finally seem to be coming through with genuine advances, at Deep Mind (Hassabis, 2019) and elsewhere, but troublingly it is not obvious why they work and when they go wrong. The engines created in the Shannon (1950) genre are at least valuable as benchmarks and have their reputations to defend. Congratulations to LEELA (Chessdom, 2019; Linscott, 2018) and to all participants for some top quality chess. We will see its equal but will we be equal to appreciating it? Helpfully, Kingscrusher (2019a, 2019b) continues to reveal the context, themes and dynamics of the games with his rich commentaries.

The e-version of this report (Haworth and Hernandez, 2019c) provides statistics beyond Table 6 and all games with some analysis including play-outs of all decisive games, some of which end more obviously than others. Semi-final LEELA-HOUDINI game 1, for example, is relatively complex in the field of TCEC-adjudicated wins.

Table 6. The shortest and longest 1-0, drawn and 0-1 games in each phase of TCEC Cup 3: ' $83 / 5$ ' indicates game 83 in the pgn, game 5 of the relevant match.

\begin{tabular}{|c|c|c|c|c|c|c|c|c|c|c|c|c|c|c|c|c|c|c|}
\hline \multirow{3}{*}{ Round - } & \multicolumn{6}{|c|}{ 1-0 } & \multicolumn{6}{|c|}{$1 / 2-1 / 2$} & \multicolumn{6}{|c|}{$0-1$} \\
\hline & \multicolumn{3}{|c|}{ Shortest } & \multicolumn{3}{|c|}{ Longest } & \multicolumn{3}{|c|}{ Shortest } & \multicolumn{3}{|c|}{ Longest } & \multicolumn{3}{|c|}{ Shortest } & \multicolumn{3}{|c|}{ Longest } \\
\hline & & ame & $\# \mathbf{m v}$ & & ame & \#mv & & ame & $\# \mathbf{m v}$ & & ame & $\# \mathbf{m v}$ & & ame & $\# \mathbf{m v}$ & & ame & $\# \mathbf{m v}$ \\
\hline 1 & $83 / 5$ & Ko-Wi & 36 & $93 / 3$ & Km-pi & 167 & $101 / 6$ & Te-An & 30 & $77 / 6$ & Va-La & 133 & $4 / 4$ & Ma-Lc & 44 & $28 / 5$ & Wa-AS & 121 \\
\hline 2 & $21 / 3$ & Ho-Fz & 39 & $29 / 5$ & St-Gi & 127 & $31 / 1$ & Et-La & 24 & $67 / 7$ & $\mathrm{Km}-\mathrm{An}$ & 127 & $4 / 4$ & Bo-Lc & 50 & $15 / 2$ & Jo-AS & 125 \\
\hline QF & $10 / 2$ & Ho-AS & 44 & $25 / 9$ & St-Et & 52 & $19 / 3$ & St-Et & 43 & $1 / 1$ & Lc-Fi & 192 & $11 / 3$ & AS-Ho & 42 & $4 / 4$ & Fi-Lc & 142 \\
\hline SF & $14 / 7$ & St-Km & 45 & $7 / 7$ & Lc-Ho & 93 & $12 / 5$ & St-Km & 59 & $4 / 4$ & Ho-Lc & 148 & - & - & - & - & - & - \\
\hline for 3rd & $5 / 5$ & Ho-Km & 38 & $1 / 1$ & Ho-Km & 62 & $7 / 7$ & Ho-Km & 45 & $2 / 2$ & Km-Ho & 128 & - & - & - & - & - & - \\
\hline Final & $8 / 8$ & St-Lc & 52 & $9 / 9$ & Lc-St & 167 & $4 / 4$ & St-Lc & 44 & $10 / 10$ & St-Lc & 144 & - & - & - & - & - & - \\
\hline Overall & 1,83 & Ko-Wi & 36 & $\mathrm{~F}, 9$ & Lc-St & 167 & 2,31 & Et-La & 24 & $\mathrm{QF}, 1$ & Lc-Fi & 192 & $\mathrm{QF}, 11$ & AS-Ho & 42 & $\mathrm{QF}, 4$ & Fi-Lc & 142 \\
\hline
\end{tabular}




\section{REFERENCES}

Aloril (2019). https://pastebin.com/Vy132VGt. Some 7-man positions mishandled by STOCKFISH.

Chessdom (2019). https://tinyurl.com/icgaj048. Interview with Alexander Lyashuk, core member of the LEELA CHESS ZERO team.

CPW (2019) https://tinyurl.com/icga046. Biographies of chess engines, authors and developers.

Hassabis, D. (2019). The Power of Self-learning systems. https://tinyurl.com/dm-dh001. Lecture at CBMM, MIT, March 20" 2019.

Haworth, G. $\mathrm{M}^{\mathrm{c} C}$. and Hernandez, N. (2019a). http://centaur.reading.ac.uk/81390/. TCEC Cup 2. Report plus statistics and pgn files. ICGA Journal, 41(2), 100-107. doi:10.3233/ICG-190104.

Haworth, G. $M^{\mathrm{c} C}$. and Hernandez, N. (2019b). http://centaur.reading.ac.uk/83156/. TCEC15: the $15^{\text {th }}$ Top Chess Engine Championship. ICGA Journal, 41(3) 153-163. doi:10.3233/ICG-190115.

Haworth, G. McC. and Hernandez, N. (2019c). http://centaur.reading.ac.uk/83157/. TCEC Cup 3. This note plus statistics and pgn files. ICGA Journal, 41(3) 168-173. doi:10.3233/ICG-190114.

Kingscrusher (2019a). https://tinyurl.com/tcec-kc002. LEELA-BOOOT, Round 2, game 1.

Kingscrusher (2019b). https://tinyurl.com/tcec-kc001. LEELA-HOUDINI, Semi-final game 1.

Linscott, G. (2018). https://github.com/LeelaChessZero/lc0/wiki LC0 on Github.

Shannon, C. E. (1950). Programming a Computer for Playing Chess. The London, Edinburgh and Dublin Philosophical Magazine, 41(314), 256-275. doi:10.1080/14786445008521796. 